\title{
A Avaliação Educacional como Objeto de Recomendações Internacionais*
}

\author{
DIRCE NEI TEIXEIRA DE FREITAS \\ Universidade Federal de Mato Grosso do Sul \\ dircenei@terra.com.br
}

\begin{abstract}
Resumo
Considerando que as recomendações de organismos internacionais operam como importantes referências político-ideológicas para a política educacional, este texto analisa o tratamento que foi dado ao tema avaliação educacional em documentos resultantes de fóruns mundiais e regionais e de comissões internacionais que trataram da questão educacional no período 1950-2000. O estudo evidenciou as alterações que ocorreram no conteúdo da recomendação da avaliação como recurso do Estado para conhecer e governar a educação básica em seu território.
\end{abstract}

Palavras-chave: avaliação educacional, avaliação institucional, órgãos internacionais, programas de avaliação do ensino superior.

\section{Resumen}

Considerando que las recomendaciones de organismos internacionales operan como importantes referencias político-ideológicas para la política educativa, este artículo analiza el tipo de abordaje del tema "evaluación educativa" en los documentos resultantes de los encuentros mundiales y regionales y de las comisiones internacionales que han tratado la cuestión educativa en el periodo 1950-2000. El estudio ha puesto en evidencia alteraciones en el contenido de la recomendación de la evaluación como recurso del Estado para conocer y gobernar la educación básica en su territorio.

Palabras-clave: evaluación educativa, evaluación institucional, órganos internacionales, programas de evaluación de la enseñanza superior.

\begin{abstract}
Because recommendations from international organizations operate as important political and ideological reference points for educational policies, this paper analyzes how educational assessment has been dealt with in documents resulting from world and regional forums and from international committees which addressed the problem of education during the period 1950-2000. The study revealed the changes that took place in the content of assessment recommendations as resources for the government to learn about and manage basic education in its territory.
\end{abstract}

Key words: educational assessment, institutional assessment, international organizations, programs for higher education assessment.

* O texto apresenta resultados de estudos realizados no âmbito de pesquisa em desenvolvimento, com vistas a doutoramento, junto à pós-graduação da Faculdade de Educação da USP, sob orientação da Prof ${ }^{a} \operatorname{Dr}^{a}$ Sandra Maria Zákia Lian Sousa. 
Os problemas de interesse comum aos Estados nacionais foram, cada vez mais, discutidos em conjunto depois da Segunda Guerra Mundial, sendo que, nos últimos vinte anos, o estabelecimento de linhas comuns de ação política se tornou mais freqüente e abrangente. Isso ensejou recomendações que - tomando a forma de princípios, de diretrizes, de planos e até mesmo de avaliações - passaram a funcionar como referências capitais para o governo da educação nos países participantes e signatários de declarações, acordos e convenções internacionais.

Foram inúmeras as reuniões de cúpulas, as conferências mundiais, as oficinas preparatórias, os estudos e decorrentes relatórios internacionais que geraram referências político-ideológicas para a educação, tanto no âmbito mundial como no regional, sempre sob o patrocínio de organismos internacionais. ${ }^{1}$

As referências político-ideológicas para a educação, delineadas com a mediação de tais organismos, têm suscitando debates e análises acerca de seus reflexos nas políticas para a educação básica brasileira. Este trabalho se propõe a evidenciar o tratamento dado ao tema da avaliação nas recomendações para a pesquisa, o planejamento e a gestão educacional formuladas em fóruns regionais e mundiais no período 1950-2000.

Para tanto, foram consultados documentos ${ }^{2}$ referenciados pelo Estado brasileiro na formulação de suas políticas educacionais, os quais são freqüentemente mencionados pela literatura que as analisa. Sem compromisso de empreender uma análise exaustiva das recomendações internacionais para a educação, o trabalho buscou responder às seguintes indagações: desde quando, como e sob quais alegações a avaliação foi recomendada como um dispositivo para o governo da educação básica? Que alterações ocorreram no conteúdo dessa recomendação no período considerado?

1 Entre eles destacam-se os seguintes: (a) agências da ONU (Unesco, PNUD, Unicef), suas comissões e escritórios regionais na área econômica (Cepal) e técnica (OIE, Orealc); (b) organizações intergovernamentais regionais (OEA e OEI); (c) organismos internacionais financeiros (Banco Mundial, BID e FMI); (d) organizações multilaterais da área econômica e produtiva (OMC e OIT).

2 Este trabalho deixou de considerar as recomendações dos organismos internacionais financeiros, pois uma farta literatura se volta para elas, especialmente as provenientes do Banco Mundial. Contemplam esse assunto as análises de: Coraggio (1992, 1994, 1995, 1996, 1996a); Torres (1996); Tommasi (1996); Soares (1996); Fonseca (1995, 1996, 1997); Lauglo (1997); Silva (2002). O trabalho também não abarca as recomendações das organizações multilaterais da área econômica e produtiva. 


\section{IMPORTÂNCIA DAS RECOMENDAÇÕES INTERNACIONAIS PARA A EDUCAÇÃO}

Nos últimos 50 anos, verificou-se a aceleração da internacionalização do processo decisório e de mundialização das atividades políticas, configurando, nas palavras de Gómez (2000, p. 159), "[...] uma densa rede de organizações e de regimes internacionais [...]".

Esse quadro não significa que os Estados estejam desaparecendo, conforme ponderou Zacher (2000), mas que eles se enredam cada vez mais em uma estrutura de interdependências e regimes. Embora alguns atores transnacionais estejam alcançando uma preeminência maior, os Estados ainda aparecem como os principais atores na ordem internacional. Todavia eles precisam trabalhar em conjunto no controle de uma variedade de interdependências, passando a existir um sistema de Estados sujeitos a uma governança internacional mínima, que abarca uma rede de regimes internacionais (formais e informais) e arranjos regulatórios ou de colaboração.

O conceito "governança", segundo Rosenau (2000, p. 20-21), na medida em que tem a ver com uma ordem global, não se limita a uma esfera singular como é o caso dos "regimes internacionais". Estes "são concebidos como arranjos ou entendimentos" traduzidos em conjuntos de princípios (implícitos ou explícitos), normas, regras e procedimentos decisórios, cujo destino é sustentar e regulamentar as atividades que ultrapassam as fronteiras nacionais. Esses arranjos e entendimentos convergem para áreas temáticas das relações internacionais, sendo especializados e concernentes a atividades bem definidas. Uma vez que funcionam sem qualquer autoridade central, "[...] podem ser descritos como formas de governança sem governo". Conforme esclarecimento do autor, a "governança" é mais ampla que os regimes internacionais e diz respeito

"[...] aos entendimentos prevalecentes nos hiatos entre os vários regimes $e$, o que talvez seja mais importante, aos princípios, às normas, às regras e aos procedimentos aplicados quando dois ou mais regimes se sobrepõem, conflitam ou de algum outro modo exigem acomodação entre interesses conflitantes."

A idéia de "governança sem governo" presume a ausência de autoridade governamental suprema no nível internacional e, ao mesmo tempo, não supõe a exclusão de governos nacionais e subnacionais. Assim, a política mundial, conforme esclarece Rosenau (2000, p. 26), envolve "[...] todas as regiões, países, relacionamentos internacionais, movimentos 
sociais e organizações privadas que se dedicam a atividades através das fronteiras nacionais".

Gómez (2000) ressalta que, nesse contexto, condicionamentos, pressões e limitações decorrentes da estrutura de poder do sistema internacional e das atividades dos organismos internacionais regionais e globais afetam, cada vez mais, a soberania e a autonomia do Estado. Todavia, o Estado permanece detentor do direito exclusivo, enquanto autoridade política, de determinar as leis, as regulações e as políticas no seu território (portanto, soberano) e, também, detentor do poder de fato de realizar objetivos políticos de maneira independente (logo, autônomo).

Com o crescimento de regimes internacionais baseados em acordos e com o aumento das atividades dos organismos internacionais, o papel dos Estados, como fontes de autoridade da lei, vai se tornando central também externamente, conforme assinalaram Hirst e Thompson (1998, p. 295), sendo que

"[...] o Estado tem o papel de fonte de legitimidade para transferir poder ou sancionar novos poderes 'acima' e 'abaixo' dele: acima, através de acordos entre os Estados para estabelecer e cumprir as formas de governabilidade internacional; abaixo, por meio de ordenação constitucional dentro de seu próprio território da relação de poder e autoridade entre governos centrais, regionais e locais e, também, os governos privados publicamente reconhecidos pela sociedade civil."

O governo da educação se encontra, portanto, mergulhado em um contexto marcado pela ruptura e ultrapassagem de fronteiras nacionais e, ao mesmo tempo, pela re-configuração do papel regulador interno do Estado. As forças internacionais influenciam externamente as políticas educacionais nacionais, sendo os quadros interpretativos nacionais moldados tanto supranacional como nacionalmente.

Assim, os impactos da atuação dos organismos internacionais e dos modelos que eles constroem sobre "a distribuição ou acessibilidade do poder" nos níveis mundial e nacional não podem ser desconsiderados, o que bem salientou Dale (2001). Segundo esse autor, tais organizações não se referenciam da mesma forma nos valores e políticas mundiais e nem deixam de ser intérpretes ativos de tais valores. Além disso, a "autoridade científica" que elas difundem depende das condições sociais do contexto em que opera, pois também a esfera local não se limita meramente a filtrar ou interpretar as mensagens da cultura mundial.

O autor ressalta que as intervenções das organizações internacionais não se restringem a mandatos políticos (atividades do Estado), mas crescentemente se voltam para as questões de "capacidade" e de 
"governança", ensejando a ascensão da atividade reguladora, enquanto declina a importância dada ao desenvolvimento do mandato estatal. Isso, na área da educação, tem propiciado a liderança dos especialistas na legitimação do Estado enquanto tal "como deve-ser", ou seja, derivação da norma: os sistemas educacionais dos países avançados (dominantes).

Contudo, mais do que os fatores culturais, as agendas estabelecidas pela economia política global orientam a elaboração de políticas educacionais, de sorte que estas não são respostas a problemas localmente percebidos. Assim, para Dale (2001, p. 151) é “[...] através da influência sobre o estado e sobre o modo de regulação, que a globalização tem os seus mais óbvios e importantes efeitos sobre os sistemas educativos nacionais". Todavia, a educação continua a ser "um assunto intensamente político ao nível nacional" e o "padrão da governação educacional" continua sob controle do Estado. trabalho.

É com esse entendimento que trato do assunto proposto para este

\section{RECOMENDAÇÕES RELATIVAS À AVALIAÇÃO EDUCACIONAL}

A pesquisa, a avaliação, a estatística, a informação e o planejamento foram recomendados, desde os anos 50, como recursos imprescindíveis para que os mais diversos países pudessem conhecer e governar a educação básica em seu território. Tais recomendações foram anunciadas como referência e impulso a iniciativas político-administrativas, como veremos a seguir.

Pode-se notar a presença da avaliação educacional como uma recomendação expressa aos países em desenvolvimento na obra da Unesco L'éducation dans le monde publicada entre 1954 e 1959, mais precisamente no volume V: Politique, législation et administration de l'éducation. Planejamento, pesquisa e avaliação educacional foram aí destacados e correlacionados, sendo as duas últimas reportadas como práticas distintas (A Educação..., 1982).

A razão então enunciada para o uso sistemático da avaliação dos sistemas de ensino consiste no seu potencial para obter informações precisas sobre os problemas educacionais. Isso porque a falta de tais informações passava a ser vista como fator a impedir o planejamento de longo prazo nos países em desenvolvimento. Assim, a avaliação da eficácia dos sistemas nacionais de ensino, pelos governos, era ali enfatizada e recomendada aos Estados-membros como condição necessária ao planejamento educacional. 
A obra ressaltou a crescente dedicação dos centros nacionais de pesquisa na busca de métodos mais aperfeiçoados para "medir os resultados" do processo educacional, principiando pela construção e padronização de testes de conhecimentos, aperfeiçoamento de provas seletivas e de exames de qualificação ocupacional.

Realçando o empenho de diversos países na produção de instrumentos para medir/selecionar/conferir, a obra acrescentou outras razões para a prática da avaliação, além das referidas ao planejamento.

A obra ressaltou a razão para a utilização da avaliação educacional em larga escala quando avalizou exames nacionais e regionais realizados por diversos países para "avaliar" os "progressos" dos alunos em vários momentos da trajetória escolar. Também salientou e avalizou a avaliação dos efeitos de inovações realizadas nos sistemas de ensino como prática em expansão - de órgãos de pesquisa de ministérios da educação, de universidades ou de organizações autônomas.

A avaliação foi questão também contemplada na Primeira Conferência Internacional de Pesquisas Educacionais, realizada em Atlantic City, Nova Jersey, de 13 a 21 de fevereiro de 1956. Promovida pela Associação Americana de Pesquisas Educacionais e contando com subvenção da Unesco, essa conferência teve funções exploratórias e buscou apontar caminho para futuras atividades em cooperação.

Segundo Abreu (1956), foi esse o primeiro evento dessa natureza realizado no mundo. Ali foram examinados os problemas de pesquisa que exigiam cooperação internacional e apontados os métodos considerados adequados para investigá-los:

“(a) levantamentos, para apuração de fatos, em determinado número de áreas geográficas ou países; (b) técnicas de estudos de 'casos' aplicadas a áreas e países selecionados; (c) análise comparativa de dados coligidos em determinado número de países; (d) experiências cuidadosamente projetadas, para aplicação em países selecionados; (e) compilação e análise de observações resultantes de pesquisas em várias fontes, nacionais e internacionais." (Relatório..., 1956, p. 130-131)

Além disso, essa conferência sugeriu processos para a ampliação e melhoria das comunicações relativas à pesquisa em educação, para a preparação e organização da pesquisa e para a preparação e treinamento de pesquisadores. Recomendou, aos participantes, o intercâmbio de informações, o desenvolvimento nacional das pesquisas educacionais, a realização de pesquisas em cooperação no nível internacional e o desenvolvimento de métodos e técnicas comuns aos países. Quanto a este último ponto recomendou à Unesco que convocasse 
"[...] uma comissão internacional de métodos de pesquisa e mensuração, na educação. A atribuição imediata desta comissão consistirá em estudar a possibilidade de formular métodos e técnicas comuns, inclusive escalas e unidades de mensuração internacionais, aplicáveis à pesquisa educacional." (Ibid., 1956, p. 157, grifo nosso)

Dois meses depois, a Unesco em colaboração com a OEA e o Governo do Peru promoveram, de 23 de abril a 5 de maio de 1956, em Lima, Peru, a Conferência Regional Latino-Americana sobre Educação Primária Gratuita e Obrigatória.

Entre as recomendações, visando à expansão da educação primária, estava a de que os países intensificassem o intercâmbio de informações e experiências entre eles e outros países do mundo, estabelecendo, para isso, centros regionais e nacionais de documentação e informação pedagógica.

Com vistas ao planejamento da extensão da educação primária, a conferência recomendou avaliação periódica dos resultados dos planos com o fim de reajustá-los e, para a administração, recomendou o aperfeiçoamento dos sistemas de controle e o levantamento periódico do censo escolar. Recomendou também estudos sistemáticos da realidade econômica, social e cultural dos países, por meio de organismos técnicos especializados, para a formulação de planos de estudos e programas (Recomendações..., 1956).

No Brasil, foi precisamente nos anos de 1950 que a pesquisa em educação ganhou forte impulso, realizando-se levantamentos, surveys e inquéritos.

Em seu discurso de posse como diretor do Instituto Nacional de Estudos Pedagógicos ${ }^{3}$ (Inep), em 4 de julho de 1952, Anísio Teixeira (1952) declarou que o compromisso desse órgão seria o de "[...] tentar uma tomada de consciência na marcha da expansão educacional brasileira, examinar o que foi feito e como foi feito, proceder a inquéritos esclarecedores e experimentar medir a eficiência ou ineficiência de nosso ensino" (p. 76, grifo nosso). Para tanto propunha

3 O Instituto Nacional de Pedagogia foi criado no bojo da nova organização do Ministério da Educação e Saúde propiciada pela Lei n ${ }^{\circ}$ 378, de 13 de janeiro de 1937, tendo iniciado seus trabalhos no ano seguinte com a denominação de Instituto Nacional de Estudos Pedagógicos, conforme dispôs o Decreto-Lei $n^{0}$ 580, de 30 de julho de 1938. Em 1972, passou a denominar-se Instituto Nacional de Estudos e Pesquisas Educacionais. Mantendo essa denominação, foi transformado em autarquia federal pela Lei $n^{\circ} 9.448$, de 14 de março de 1997. Passou a denominar-se Instituto Nacional de Estudos e Pesquisas Educacionais Anísio Teixeira pela Lei $\mathrm{n}^{\circ} 10.269$, de 29 de agosto de 2001 . 
"[...] medir o sistema educacional em suas dimensões mais íntimas, revelando ao país não apenas a quantidade das escolas, mas a sua qualidade, o tipo de ensino que ministram, os resultados a que chegam no nível primário, no secundário e mesmo no superior." (Ibid, p. 78)

Desde 1953 o Inep realizou, por meio da Campanha de Inquéritos e Levantamentos do Ensino Médio e Elementar (Cileme), estudos e pesquisas sobre o ensino nos Estados e articulou com a Unesco a colaboração de especialistas estrangeiros que, com os brasileiros, compuseram o corpo científico e técnico dos Centros de Pesquisas Educacionais criados no período 1955-1957.

Cabe lembrar que, em setembro de 1952, Anísio Teixeira propôs a William Beatty, diretor do Departamento de Educação da Unesco, a realização, por especialistas desse organismo, de um survey sobre a situação educacional do País, com vistas a gerar informações que propiciassem planejar medidas de longo alcance para a reconstrução educacional pósEstado Novo. Essa proposta, em agosto de 1953, tomou a forma de uma instituição permanente, com o relatório de Charles Wagley e Carl Withern, sendo nomeada provisoriamente como "Centro de Altos Estudos Educacionais". Em janeiro de 1954, Anísio Teixeira apresentou a William Carter (da Unesco) os objetivos e finalidades do futuro centro, o que seria base para recrutamento dos especialistas que seriam enviados ao País pelo organismo. Em fins de 1954, chegava ao Brasil, para cooperar na organização do centro, o sociólogo britânico Bertram Hutchinson. Em abril de 1955, Otto Klineberg (Unesco) sugeria o nome pelo qual o centro viria a ser criado e propunha a realização de um "mapa cultural" e um "mapa educacional" brasileiros. Charles Wagley (Columbia University), colaborador de Anísio Teixeira e equipe da Capes, desempenhou importante papel na criação e implantação do Centro Brasileiro de Pesquisas Educacionais (CBPE) e Centros Regionais (Ferreira, 2001). ${ }^{4}$

No período 1956-1964, conforme Gouveia (1971), foram realizados levantamentos, surveys e inquéritos que mapearam a administração das redes de escolas, informaram sobre a situação de funcionamento das escolas, sobre resultados quantitativos do ensino (índices de aprovação, repetência, matrícula e evasão) e sobre as relações entre escola e realidade local.

4 Os Centros de Pesquisas Educacionais, criados em 1955, foram "desestimulados" desde 1964 e extintos em 1972. Participaram desses centros intelectuais de destaque no cenário brasileiro entre os quais cumpre destacar: Antonio Candido, Darcy Ribeiro, Fernando de Azevedo, Florestam Fernandes e Gilberto Freyre (Paoli, 1994). 
Voltando a olhar para o contexto internacional, verificamos que a avaliação foi também recomendada quando esteve em pauta a questão do planejamento educacional, conforme se mostra a seguir.

No período 1956-1965, a Unesco realizou conferências regionais que culminaram na Conferência Internacional sobre Planejamento da Educação, realizada de 6 a 14 de agosto de 1968 em Paris.

Na região latino-americana, foram importantes a Segunda Reunião Interamericana de Ministros de Educação de 1956 e o Seminário Interamericano sobre Planejamento Integral da Educação de 1958.

A Segunda Reunião Interamericana de Ministros de Educação, realizada de 3 a 9 de maio de 1956 em Lima, Peru, recomendou a aplicação de técnicas para o planejamento integral da educação (compreendendo todos os níveis de ensino) de modo a atender à realidade do país (Abreu, 1962). A resolução da reunião recomendou a avaliação do ensino primário, com vistas a reformas e inovações que permitissem ao sistema atender com mais eficiência a um maior número de alunos. Devido à importância da educação pública para o desenvolvimento dos países, os ministros consideravam imperioso que sua organização e funcionamento fossem avaliados e reajustados regularmente para alcançar o máximo rendimento dos recursos disponíveis (Recomendações..., 1956).

Assim, os países deveriam avaliar os seguintes aspectos: legislação e regulamentação; localização das escolas em relação à distribuição da população em idade escolar, acessibilidade e vias de comunicação; práticas de matrículas; trabalho realizado por diferentes tipos de escolas; política de estabelecimento de novas escolas; organização e aproveitamento das escolas; emprego dos recursos e possibilidades do lugar. Outras recomendações foram a de estudos técnicos sobre a organização e administração da educação pública para melhorar a sua eficiência e a de organização da estatística escolar com rigor científico, de modo a obter resultados passíveis de comparação entre os países (Ibid.).

Atendendo a recomendação dessa reunião, a Unesco e a OEA organizaram o Seminário Interamericano sobre Planejamento Integral da Educação, que foi realizado no ano de 1958 em Washington. Esse seminário constituiu-se marco da inserção do planejamento no projeto de Expansão e Aperfeiçoamento do Ensino Primário na América Latina. Ele recomendou que a educação fosse considerada como parte essencial do desenvolvimento, devendo ser planejada com base em diagnóstico da situação socioeconômica e educacional, com atenção especial à educação básica, à repetência escolar, à preparação de técnicos e à qualidade do ensino. A avaliação deveria prestar-se, portanto, a uma função diagnóstica 
sob a ótica vigente no planejamento, qual seja: a da racionalização associada à técnica e à prevalência do desenvolvimento econômico.

Buscando tratar das relações entre a educação e a situação econômica, social e demográfica latino-americana e com vistas a definir objetivos de um "plano decenal" para o desenvolvimento da educação na região, a Unesco, a Cepal, a OIT, a FAO e a OEA patrocinaram a Segunda Conferência sobre Educação e Desenvolvimento Econômico e Social na América Latina $^{5}$, realizada de 5 a 19 de março de 1962 em Santiago do Chile. Enfatizando a estrutura e administração dos serviços educacionais com vistas ao máximo aproveitamento dos recursos disponíveis, essa conferência incluiu entre suas recomendações a de que os governos "iniciassem estudos e investigações" como procedimento para propiciar a relação da política educacional com as metas nacionais de desenvolvimento econômico e social. A conferência recomendou alta prioridade ao planejamento da educação, aos métodos de avaliar os gastos em educação e respectivos benefícios, à formulação de diagnósticos da situação socioeconômica e educacional e às técnicas de investigação das necessidades educacionais relacionadas ao desenvolvimento econômico e social nacional (Abreu, 1962; Planificação..., 1971).

No conjunto, é possível notar que as recomendações para a região subordinam a pesquisa, o planejamento e a avaliação educacional ao desenvolvimento econômico e ressaltam a avaliação do custo/benefício da

5 A decisão de realizar essa conferência ocorreu no Seminário Interamericano sobre Planejamento Integral da Educação, realizado em Washington em julho de 1958. Antecederam-na várias reuniões das quais participaram "peritos em educação e em ciências sociais", que discutiram e fixaram os temas a tratar. A reunião de outubro de 1959 ocorreu no Rio de Janeiro. Das quatro reuniões realizadas, a que teve maiores conseqüências para essa conferência foi a Reunião Extraordinária do Conselho Interamericano Econômico e Social da OEA, realizada em Punta Del Este, Uruguai, de 5 a 17 de agosto de 1961, com o intuito de fixar as bases para a efetivação da política da Aliança para o Progresso. Todos os países latino-americanos estiveram representados por seus Ministros de Economia ou Finanças. Essa reunião propôs maior integração dos planos de desenvolvimento educacional com os programas nacionais de desenvolvimento (Abreu, 1962). Uma das resoluções da reunião consistiu no Plano Decenal de Educação da Aliança para o Progresso. A Aliança para o Progresso consiste num Programa da Organização dos Estados Americanos (OEA) que, entre 1958 e 1970, gerou ajuda externa a países do continente americano, destinada ao enfrentamento de desigualdades sociais e econômicas, tendo em vista evitar a disseminação de regimes socialistas na região. De 1958 a 1962, as entidades patrocinadoras da Conferência sobre Educação e Desenvolvimento Econômico e Social na América Latina prepararam um "copioso acervo de documentos de trabalho para a conferência" e os países latino-americanos apresentaram informes e relatórios sobre a sua conjuntura educacional vinculada a análises de sua situação econômica e sociocultural. 
educação e das demandas econômicas e sociais. A avaliação aparece principalmente como recurso para informar sobre a funcionalidade econômica da educação.

No Brasil, a adoção do planejamento educacional ocorreu, segundo Abreu (1962), com certa morosidade, ainda que pelo Decreto ${ }^{\circ} 51.152$ de 5 de agosto de 1961 (modificado pelo de $\mathrm{n}^{\circ}$ 154, de 17 de novembro de 1961) tenha sido instituída a Comissão Nacional de Planejamento (Coplan).

O primeiro Plano Nacional de Educação, elaborado em 1962 pelo Conselho Federal de Educação e concebido como mero instrumento de redistribuição de recursos, acabou, de forma implícita, vinculando a questão da "medida-avaliação" a esse escopo.

Segundo Arapiraca (1982, p. 46), as recomendações dessas conferências "[...] foram retomadas e aplicadas ao Brasil com um realismo ainda maior que a própria letra fria daqueles documentos [...] diante do alinhamento em que se posicionou o Brasil em 1964", com a instalação do Regime Militar.

As conferências regionais culminaram na Conferência Internacional sobre o Planejamento da Educação, a qual foi organizada pela Unesco e realizada em Paris, no período de 6 a 14 de agosto de 1968.6 Essa conferência conclamou a novos esforços para se alcançar, tanto nos estadosmembros como na cooperação internacional, importantes progressos em matéria de planejamento e desenvolvimento da educação. Para isso, recomendou-lhes promover a participação da sociedade, tanto na identificação dos objetivos do sistema educacional como na preparação de seu desenvolvimento; realizar o planejamento educacional em estreito contato e cooperação com docentes e órgãos administrativos competentes, criando mecanismos para tanto; promover a importância da inovação e do planejamento da educação; considerar as vantagens da descentralização da iniciativa para adequar planos às necessidades locais e regionais; estudar a necessidade de um serviço de pesquisa educacional no País que identificasse, compilasse, avaliasse e difundisse inovações surgidas nos sistemas de ensino (Planificação..., 1971).

Aos organismos internacionais convidou a reservar recursos orçamentários, conforme se vê em Planificação... (1971, p. 233-234), para, entre outras coisas, elaboração de "[...] métodos de análise e aferição para avaliar os efeitos da educação sôbre o desenvolvimento geral, sem se

6 Participaram da Conferência Internacional sobre o Planejamento da Educação de 1968 um total de 95 dos 125 estados-membros, além de 8 organizações internacionais, 8 organizações intergovernamentais e 13 organizações não-governamentais. 
limitar, no entanto, à educação escolar" e para "[...] normalizar as estatísticas e a informação preparada pelos estados-membros, a fim de estabelecer indicadores comparáveis [...]" de modo a permitir "[...] uma avaliação do funcionamento do sistema de educação e dos efeitos [...] sobre o desenvolvimento econômico, social, cultural e político".

No Brasil, durante o período do Regime Militar (1964-1984), o enfoque econômico dos processos de modernização da administração pública estendeu-se para as políticas e a administração educacional, tendo como referência os movimentos internacionais da economia da educação, da teoria do capital humano e da planificação de recursos humanos (Sander, 2001). O planejamento educacional ganhou, então, ênfase como componente setorial do planejamento governamental.

Nesse contexto, a avaliação e a informação estatística passaram a ser destacadas como condições necessárias ao planejamento, pois são meios indispensáveis para a ampliação de conhecimentos essenciais à eficácia dessa intervenção estatal no desenvolvimento.

A princípio proposta como instrumento de integração e racionalização do planejamento e da racional utilização de recursos, a avaliação passou a ser prescrita como estratégia de modernização institucional-administrativa, assim como de controle da efetivação de programas / projetos e ações do governo central (1964-1979). Com a crise do planejamento e a subseqüente introdução do denominado "planejamento participativo (1980-1984), ela foi anunciada como meio para assegurar-se a "ótica dos beneficiários" e, no contexto da transição para a democracia (1985 a 1989), apareceu como recurso necessário à redefinição das funções da escola, pois viabilizaria o estabelecimento de padrões mínimos de desempenho em nível nacional, que se tornara imperativo com a descentralização. Assim, a informação propiciada pela "medida-avaliação" passou a ser declarada recurso indispensável para o alcance de objetivos de democratização da educação e de melhoria da qualidade do ensino.

Os anos de 1990 registraram a intensificação das recomendações internacionais em decorrência da aceleração do processo de internacionalização do capitalismo, no bojo do qual se verificou o alargamento da internacionalização do processo decisório e da mundialização das atividades políticas. Nesse contexto, foram especialmente importantes as recomendações mencionadas a seguir.

A Conferência Mundial de Educação para Todos de Jomtien, Tailândia, realizada no início de março de 1990, teve como patrocinadores o PNUD, a Unesco, o Unicef e o Banco Mundial. Essa conferência estabeleceu a satisfação das necessidades básicas de aprendizagem de todos como o objetivo último do compromisso firmado pelos 155 países participantes. 
Para isso seria preciso tornar a educação básica eqüitativa, oferecendo oportunidades a todos de alcançar e manter um padrão mínimo de qualidade da aprendizagem. A educação básica deveria, assim, centrar-se na aquisição e nos resultados da aprendizagem, sendo, para isso, necessário definir "[...] níveis desejáveis de aquisição de conhecimentos e implantar sistemas de avaliação de desempenho" (Declaração..., 1991, p. 5).

Estabelecendo as diretrizes para a implementação dos compromissos firmados com a Declaração Mundial sobre Educação para Todos, o Plano de Ação indicou como uma das ações prioritárias em âmbito nacional o "aperfeiçoamento das capacidades gerenciais, analíticas e tecnológicas" dos países. Quanto a isso, uma das urgências destacadas foi a de construir base de informações e conhecimentos "vitais" para a preparação e execução de seus planos de ação. A avaliação dos processos e resultados deveria fornecer os dados de base para um sistema de informação administrativa para a educação básica. Para tanto, tornava-se necessário que os países elaborassem e aperfeiçoassem "[...] sistemas eficazes para a avaliação do rendimento individual dos educandos e do sistema de ensino" (Plano..., 1991, p. 9).

A avaliação em larga escala era aí enfatizada como condição necessária tanto para o planejamento como para a gestão da educação básica nos diversos países. Em particular, responderia ao imperativo do enfoque nos resultados da aprendizagem, ou seja, no desempenho dos alunos e dos sistemas de ensino.

$\mathrm{O}$ Congresso Internacional sobre "Planejamento $e$ Gestão do Desenvolvimento da Educação" - realizado no México, no final de março de 1990, sob patrocínio da Unesco e em continuação à Conferência Internacional sobre o Planejamento da Educação, de 1968 - estabeleceu recomendações para as atividades de planejamento e gestão da educação com vistas a melhorar os sistemas educacionais, tendo examinado conseqüências das decisões tomadas em Jomtien, no início daquele mês (Planeamiento..., 1998).

Nesse fórum, o debate sobre a modificação do papel do Estado concluiu que lhe caberia fixar os objetivos ${ }^{7}$, garantir recursos apropriados, avaliar os processos e resultados para verificar a qualidade da educação oferecida, comunicar as informações e fazer frente às situações de emergência por meio de adequado planejamento. Compartilhando responsabilidades educacionais com outras esferas da sociedade, caberia ao Estado estabelecer a coerência do conjunto. Para isso, necessitaria dispor de instrumentos de avaliação e de controle que permitissem tanto a coerência dos objetivos gerais como o respeito à autonomia dos atores.

7 Ou seja, qual o saber mínimo a difundir de modo que cada indivíduo possa prosseguir sua formação por seus próprios meios. 
Tal avaliação deveria se referir ao conjunto do campo educacional, ou seja, à avaliação da aprendizagem dos alunos, da qualidade dos agentes, das políticas e de sua execução, das unidades de produção, dos resultados da educação e das instituições nacionais/subnacionais que elaboram políticas educacionais. As metodologias de investigação e avaliação deveriam ser desenvolvidas com a finalidade de medir e apreciar dados qualitativos.

Como parte integrante da tomada de decisão, da planificação e da gestão a avaliação seria realizada nas fases de formulação, de execução de programas e projetos e posterior à execução. Isso foi considerado essencial para um controle contínuo do sistema educacional no que diz respeito a seus insumos e resultados, pois permitiria transformar potenciais fracassos em êxito ou em fracassos menos graves. Dever-se-ia, nesse processo, levar em conta as exigências dos contextos nacionais, regionais e locais. Isso requereria considerar, entre outros, as culturas organizacionais e a própria história institucional, pois a não-adaptação ao meio poderia condenar ao fracasso os melhores sistemas avaliativos.

A conferência recomendou, aos países participantes, reforçar os sistemas de informação (incluindo novos indicadores, uso mais sistemático de dados e uma ampliação das análises qualitativas), desenvolver novos canais de investigação e buscar maior conhecimento dos resultados da aprendizagem.

No contexto latino-americano, recomendações delineadas no ingresso dos anos de 1990 apontaram a avaliação como recurso imprescindível para uma nova gestão educacional nos países da região.

A Comissão Econômica para a América Latina (Cepal) e o Escritório Regional de Educação da Unesco (Orealc), com base na proposta Transformação Produtiva com Eqüidade formulada em 1990, elaboraram o documento intitulado Educação e Conhecimento: eixo da transformação produtiva com eqüidade, no qual eles afirmaram, segundo síntese apresentada por Ottone (1993, p. 13), a necessidade de "repensar" o papel do Estado, de modo a abandonar o enfoque de "administração burocrática dirigista e centralizadora" e privilegiar a "orientação estratégica, a regulação à distância, o impulso das autonomias e a avaliação dos resultados".

O papel compensador do Estado estaria a requerer (Ibid., p. 13), entre outras medidas, a passagem de "sistemas e funções educativos fechados" e "não avaliados" para "[...] uma visão aberta que os defina e avalie em função dos benefícios que eles podem trazer à economia, à sociedade e à cultura", assim como deslocar a ênfase da quantidade para a "[...] primazia da qualidade, da efetividade e dos resultados". 
A IV Reunião Regional Intergovernamental do Projeto Principal de Educação na América Latina e no Caribe (Promedlac IV) - realizada em Quito, Peru, em abril de 1991 - tendo examinado as realizações e obstáculos encontrados no biênio 1989-1991, firmou, com a Declaração de Quito, linhas norteadoras para uma nova etapa de desenvolvimento educacional por meio de um novo estilo de gestão. Este deveria, num contexto de carência de recursos, responder aos desafios da eficácia, eqüidade e eficiência dos sistemas de ensino (Proyecto..., 1991).

Para isso, os países da região concordaram em robustecer sua integração regional e seus vínculos bilaterais; promover transformação profunda na gestão tradicional, articulando a educação com as demandas econômicas, sociais, políticas e culturais, de modo a romper com o isolamento das ações educacionais; criar e desenvolver mecanismos e estratégias de concerto entre diferentes setores da administração pública, entre esta e organismos não-governamentais, empresas privadas, meios de comunicação, organizações sindicais e comunitárias, igrejas e as próprias famílias; modificar os estilos de planificação e de administração, de modo a vinculá-las com as necessidades sociais e com o caráter intersetorial das ações educacionais.

Para aumentar a capacidade de gestão, entre outras medidas, seria preciso impulsionar processos de descentralização, regionalização e desconcentração, desenhar ágeis mecanismos de avaliação de resultados e sistemas de informação e investigação para a tomada de decisões. A introdução de diferentes modalidades de avaliação foi apontada como medida com alto potencial de dinamização dos sistemas educacionais, pois permitiriam tornar mais visíveis os impactos individuais e sociais dos processos educacionais, com o propósito de fomentar uma melhor qualidade dos mesmos.

A $V$ Reunião Regional Intergovernamental do Projeto Principal de Educação na América Latina e no Caribe (Promedlac V), realizada em Santiago do Chile em 1993, propôs que se avançasse na caracterização de um novo modelo educacional, identificando os principais elementos de uma estratégia que se constituísse marco para transformar a educação em fator chave do desenvolvimento. Assinalou que o Estado centralizado seguia liberando-se de funções tradicionais para se concentrar em áreas estratégicas como a formulação de políticas e incentivos, o monitoramento das mesmas, a avaliação do resultado da ação educacional, a identificação de inovações, a implementação de ações de compensação e investigação em áreas estratégicas (Reunião..., 1993; Hacia..., 1995).

Ressaltou-se aí a importância da existência de mecanismos de informação e avaliação do rendimento escolar e dos docentes, bem como da 
difusão pública de seus resultados, para o bom funcionamento interno e externo de um sistema educacional. Isso propiciaria aos usuários demandar maior qualidade do ensino e aos estabelecimentos melhorar seu desempenho, fazendo com que as autoridades concentrassem sua ação onde os rendimentos são mais baixos e podem afetar a eqüidade do sistema.

Medir desempenhos seria um meio para incentivar melhorias e assegurar destinação e uso eficiente de recursos, viabilizando-se uma gestão responsável. Acrescenta-se à avaliação de resultados a apreciação da eficiência externa da educação do ponto de vista dos indivíduos e da sociedade. Para isso, deveriam ser adequados permanentemente as estruturas e os mecanismos institucionais de avaliação, assegurando-se a identificação de responsabilidades individuais na gestão.

Assim, a Declaração de Santiago estabeleceu como um dos objetivos para o período 1993-1996 desenvolver uma gestão responsável pelos resultados como fator crucial da modernização da administração educacional. Isso exigiria grande capacidade de definição de alvos e indicadores de rendimento a alcançar, bem como a aplicação sistemática de procedimentos de avaliação de resultados obtidos com os programas e projetos executados. Desse modo, poder-se-ia, permanentemente, retroalimentar e aperfeiçoar o sistema de administração e introduzir incentivos que contribuiriam para a eficiência de seu desempenho.

Fica claro que a valorização da avaliação educacional, nos primeiros anos de 1990, se relaciona com a ênfase na mudança do papel do Estado.

Em novembro de 1991 a Conferência Geral da Unesco recomendou a convocação de uma comissão internacional para refletir sobre a educação no século XXI. Criada em 1993, a Comissão Internacional sobre Educação para o Século XXI apresentou, em 1996, seu Relatório (conhecido como Relatório Jacques Delors) no qual apontou a avaliação rigorosa dos sistemas educacionais como um dispositivo indispensável ao debate sobre as opções educacionais nos países, na medida em que possibilitaria à sociedade fazer tais opções (Educação..., 1998).

Para tanto, a avaliação recomendada seria ampla e, portanto, não restrita à dimensão econômica (custo/benefício), considerando-se a oferta, o ensino, o financiamento, a gestão, a orientação geral e o prosseguimento dos objetivos de longo prazo. Seria também uma avaliação objetiva e pública, de forma a apreender a situação do sistema educativo e seu impacto na sociedade.

A comissão apontou razões de ordem política e pedagógica para tal avaliação, quais sejam: tornar os debates no parlamento e nos meios de comunicação um debate da sociedade; propiciar a prestação de contas dos 
orçamentos públicos para a educação; oferecer aos diferentes "atores" um conhecimento "mais perfeito" de sua atuação; e operar na difusão de inovações (Educação..., 1998).

Os dispositivos de avaliação, mais que propiciar o planejamento educacional de longo prazo e servir aos processos de gestão educacional, são enfatizados, nesse momento, como instrumentos de um processo democrático de escolha das opções educacionais pela sociedade. A avaliação passa a ser ressaltada não mais apenas como um recurso de administração dos governos segundo um novo papel do Estado, mas como um recurso da própria sociedade na definição dos rumos da educação que reconheça como necessária e desejável, a partir de um dimensionamento daquela que existe de fato. Aponta, pois, para uma direção na qual se pode pensar a avaliação como recurso de uma administração pública, entendida esta para além do sentido estrito de administração governamental ou estatal. Com a alteração da perspectiva, a avaliação passa a ser considerada uma questão de interesse local e global, nacional e subnacional, nacional e internacional.

No Brasil, os anos de 1990 registraram a instituição e consolidação de um sistema nacional de avaliação da educação básica (o Saeb), a instituição de exames (Enem e Encceja), a modernização das estatísticas educacionais, a criação de um sistema integrado de informações educacionais (SIEd), a participação em iniciativas internacionais de avaliação educacional, assim como a inscrição da avaliação como prioridade do planejamento estratégico da educação e uma maior presença da questão da avaliação na pesquisa educacional. Para isso, a reforma administrativa propiciou a criação de condições institucionais e políticas para o exercício regular das práticas de medida e avaliação educacional. A publicidade oficial e a utilização de mídias foram estratégicas para a disseminação do imperativo e das promessas da avaliação educacional, bem como para legitimar a regulação da educação por essa via.

No período 2000-2004, diversas medidas foram adotadas ou anunciadas com vistas a dois propósitos: aperfeiçoamento das iniciativas de avaliação já consolidadas e expansão do alcance de tais iniciativas tendo como objetivo adentrar à unidade escolar e mobilizá-la para a prática da mensuração e da avaliação.

\section{CONCLUSÃO}

A análise documental mostrou que a avaliação em larga escala apareceu nas recomendações internacionais para a educação desde meados 
dos anos de 1950. Geralmente relacionada à pesquisa e ao planejamento, foi apontada como condição necessária para que os Estados pudessem conhecer e governar a educação, uma vez que lhes permitiria diagnosticar, conferir, regular, selecionar, avalizar e comparar dados sobre as condições e os resultados do sistema educacional.

Outra constatação propiciada pela análise diz respeito à ênfase dada, desde os anos de 1960, ao sentido econômico da avaliação, embora ele estivesse presente nas recomendações dos anos de 1950.

Os dados evidenciaram que, nos anos de 1990, a avaliação foi recomendada como condição necessária ao planejamento estratégico e à gestão estratégica, como recurso para uma gestão menos governamental/estatal e mais "pública" e "democrática", como recurso para profissionalizar o servidor público, como questão de interesse para a relação entre os âmbitos subnacional, nacional e internacional.

A avaliação educacional recebeu ênfase como dispositivo de regulação e de modernização da gestão educacional, variando, em diferentes momentos, o agente principal a promovê-la: ora o governo central, ora este sob uma agenda globalmente estruturada, ora a sociedade comandada pelo governo central sob uma agenda globalmente estruturada.

As variações nos motivos para a utilização da avaliação como expediente de governo da educação básica parecem estar relacionados a distintos compromissos do Estado. No caso brasileiro, foi primeiramente coerente com compromissos priorizados pelo Estado nacionaldesenvolvimentista e, mais recentemente, pelos compromissos de um Estado instado, pela própria globalização e pela força do ideário neoliberal, a se tornar um "Estado competitivo".

Não há dúvidas de que as recomendações político-ideológicas internacionais mencionadas neste trabalho estimularam a utilização da avaliação como dispositivo de regulação educacional voltada para a modernização da gestão, no Brasil. Também não há dúvida de que a formulação, a implementação e a avaliação de políticas públicas de educação são atravessadas, no âmbito nacional e subnacional, por intrincados processos nos quais interagem múltiplas agências e atores sob condicionamentos políticos, econômicos, administrativos, institucionais e culturais. Formulação, implementação e avaliação que, por meio de processos dialéticos intra e inter esferas do governo (em particular nas áreas econômica, social e educacional), expressam resultados de escolhas e decisões que possibilitam nexos entre níveis macro, meso e micro implicados na regulação da educação. Tal foi o caso da introdução da avaliação como uma importante via de regulação da educação básica brasileira. 


\section{REFERÊNCIAS BIBLIOGRÁFICAS}

ABREU, Jayme. Educação e desenvolvimento sócio-econômico na América Latina: expressão de uma Conferência. Revista Brasileira de Estudos Pedagógicos, v. XXXVII, n. 86, p. 5-31, abr./jun. 1962.

Pesquisa e planejamento em educação. Revista Brasileira de Estudos Pedagógicos, v. XXVI, n. 63, p. 100-122, jul./set. 1956.

A EDUCAÇÃO NO MUNDO: Política, legislação e administração educacional, v. 3. São Paulo: Saraiva, 1982.

ARAPIRACA, José Oliveira. A USAID e a educação brasileira. São Paulo: Autores Associados, 1982.

CORAGGIO, José Luis. Desenvolvimento humano e educação. São Paulo: Cortez, 1996. 277 p.

Propostas do Banco Mundial para a educação: sentido oculto ou problema de concepção? In: TOMMASI, L. de; WARDE, M. J.; HADDAD, S. O Banco Mundial e as políticas educacionais. São Paulo: Cortez, 1996a. p. 75123.

Economia y educación en América Latina: notas para una agenda para los 90. In: REUNIÃO DEL GRUPO DE TRABAJO DE EDUCACIÓN POPULAR Y ECONOMÍA, 1., 1992, Santiago do Chile. Santiago do Chile: CEAAL, 1992. Disponível em: <http:/www.fronesis.org>. Acesso em: jan. 2000.

. Desarrollo humano y politica educativa en la ciudad latinoamericana. In: SEMINÁRIO INTERNACIONAL EDUCAÇÃO POPULAR E UNIVERSIDADE, 3., 1994, João Pessoa. Disponível em: $<$ http:/www.fronesis.org >. Acesso em: jan. 2000.

- Educación y modelo de desarrollo. In: SEMINÁRIO INTERNACIONAL SOBRE POLÍTICAS EDUCATIVAS EN AMÉRICA LATINA, 1994, Santiago do Chile. Políticas educativas en América Latina. Lima: TAREA-CEAAL, 1995. Disponível em:<http:/www.fronesis.org> Acesso em: jan. 2001. 
DALE, Roger. Globalização e educação: demonstrando a existência de uma "cultura educacional mundial comum" ou localizando uma "agenda globalmente estruturada para a educação"? Educação, Sociedade e Culturas, n. 16, p. 133-169, Lisboa, 2001.

DECLARAÇÃO MUNDIAL SOBRE EDUCAÇÃO PARA TODOS. Conferência Mundial de Educação para Todos, 1990, Jomtien. Brasília: Unicef, 1991.

EDUCAÇÃO: UM TESOURO A DESCOBRIR. Relatório para a Unesco da Comissão Internacional sobre Educação para o século XXI. São Paulo: Cortez, 1998.

FERREIRA, Márcia dos S. O Centro Regional de Pesquisas Educacionais de São Paulo (1956-1961). São Paulo, 2001. Dissertação (Mestrado em Educação) Universidade de São Paulo. 193p. Disponível em: <http://www.teses.usp. $\mathrm{br} /$ teses/disponiveis/48/48134/tde-29102001-143059/publico/tde.pdf $>$.

Acesso em: 25 ago. 2004.

FONSECA, Marília. O Banco Mundial e a educação brasileira: uma experiência de cooperação internacional. In: OLIVEIRA, Romualdo Portela de. (org.). Política educacional: impasses e alternativas. São Paulo: Cortez, 1995. p.85-121.

. O Financiamento do Banco Mundial à educação brasileira: vinte anos de cooperação internacional. TOMMASI, Livia de; WARDE, Mirian J.; HADDAD, Sérgio. O Banco Mundial e as politicas educacionais. São Paulo: Cortez, 1996. p. 229-251.

O Banco Mundial e a gestão da educação brasileira. In: OLIVEIRA, Dalila Andrade. (org.). Gestão democrática da educação: desafios contemporâneos. Rio de Janeiro: Vozes, 1997, p. 46-63.

GÓMEZ, José M. Globalização da política: mitos, realidades e dilemas. In: GENTILI, P. (org.). Globalização excludente. 2. ed. Petrópolis: Vozes, 2000b. p. 128-179.

HACIA UMA NUEVA ETAPA DE DESARROLLO EDUCATIVO. Boletín 31. Proyecto Principal de Educación para América Latina y el Caribe. Oficina Regional de Educación de la UNESCO para América Latina y el Caribe. Unesco/Orealc, La Habana, Cuba, 6-10 fev. 1995.

HIRST, Paul; THOMPSON, Grahame. Globalização em questão. 3. ed. Petrópolis: Vozes, 1998, 364p. 
LAUGLO, Jon. Crítica às prioridades e estratégias do Banco Mundial para a educação. Cadernos de Pesquisa, São Paulo: FCC, n. 100, p. 11-36, mar. 1997.

OTTONE, Ernesto. Educação e conhecimento: eixo da transformação produtiva com eqüidade (uma visão sintética). Brasília: MEC/Inep, 1993. $16 \mathrm{p}$.

PAOLI, Niuvenius J. Sobre as relações entre política educacional e pesquisa científica no Brasil: a proposta dos Centros de Pesquisas Educacionais do Instituto Nacional de Estudos Pedagógicos (Inep) nos anos 50. Políticas educacionais na América Latina, 2. ed. Cadernos CEDES, Campinas, n. 34, p.69-77, 1994.

PLANEAMIENTO Y GESTIÓN DEL DESARROLHO DE LA EDUCACIÓN. Informe Final. Congresso Internacional Planeamiento y Gestión del Desarolho de la Educación, México, 23-30 mar. 1990. Unesco. Disponível em:<www.unesco/> . Acesso em: 10 out. 1998.

PLANIFICAÇÃO DA EDUCAÇÃO: um levantamento mundial de problemas e perspectivas Conferência Internacional sobre o Planejamento da Educação, Unesco, Paris, 1968. Rio de Janeiro: FGV, 1971.

PLANO DE AÇÃO PARA SATISFAZER AS NECESSIDADES BÁSICAS DE APRENDIZAGEM. Conferência Mundial de Educação para Todos, 1990, Jomtien. Brasília: Unicef, 1991.

PROYECTO PRINCIPAL DE EDUCACIÓN EN AMÉRICA LATINA Y EL CARIBE. Orealc/Unesco, Boletín n. 24, abr. 1991.

RECOMENDAÇÕES DA SEGUNDA REUNIÃO INTERAMERICANA DE MINISTROS DE EDUCAÇÃO. Revista Brasileira de Estudos Pedagógicos, v. XXVI, n. 63, p. 179-201, jul./set. 1956.

RELATÓRIO PRELIMINAR DA PRIMEIRA CONFERÊNCIA INTERNACIONAL DE PESQUISAS EDUCACIONAIS. Revista Brasileira de Estudos Pedagógicos, v. XXVI, n. 63, p. 123-178, jul./set. 1956.

REUNIÃO DO COMITÊ REGIONAL INTERGOVERNAMENTAL DO PROJETO PRINCIPAL DE EDUCAÇÃO PARA A AMÉRICA LATINA E O CARIBE, 1993, Santiago do Chile. PROMEDLAC V. Brasília: MEC, 1993. 32p. 
ROSENAU, James N. Governança, ordem e transformação na política mundial. In: ROSENAU, James N.; CZEMPIEL, Ernest-Otto. (orgs.). Governança sem governo: ordem e transformação na política mundial. Brasília: UnB, 2000.

SANDER, Benno. Política e gestão da educação no Brasil: momentos e movimentos. Revista Brasileira de Políticas Públicas em Educação, São Bernardo do Campo, ANPAE, v. 17, n. 12, p. 263-276, jul./dez. 2001.

SILVA, Maria Abadia da. Intervenção e consentimento: a política educacional do Banco Mundial. Campinas: Autores Associados, 2002.

SOARES, Maria Clara Couto. Banco Mundial: políticas e reformas. In: TOMMASI, L. de; WARDE, M. J.; HADDAD, S. O Banco Mundial e as políticas educacionais. São Paulo: Cortez, 1996. p. 15-40.

TEIXEIRA, Anísio. Discurso de posse do Professor Anísio Teixeira no Instituto Nacional de Estudos Pedagógicos. Revista Brasileira de Estudos Pedagógicos, v. XVII, n. 46, p. 69-79, 1952.

Centro Brasileiro de Pesquisas Educacionais. Revista Brasileira de Estudos Pedagógicos, v. XXV, n. 61, p. 145-153, jan./mar. 1956.

TOMMASI, Livia de. Financiamentos do Banco Mundial no setor educacional brasileiro: os projetos em fase de implementação. In: TOMMASI, Livia de; WARDE, Mirian J.; HADDAD, Sérgio. O Banco Mundial e as políticas educacionais. São Paulo: Cortez, 1996. p. 195-227.

TORRES, Rosa Maria. Melhorar a qualidade da educação básica? As estratégias do Banco Mundial. In: TOMMASI, Livia de; WARDE, Mirian J.; HADDAD, Sérgio. O Banco Mundial e as políticas educacionais. São Paulo: Cortez, 1996. p. 125-193.

ZACHER, M. W. Os pilares em ruína do templo de Vestfália: implicações para a governança e a ordem internacional. In: ROSENAU, J. N.; CZEMPIEL, E. (orgs.). Governança sem governo: ordem e transformação na política mundial. Brasília: UnB, 2000.

Recebido em: junho 2004

Aprovado para publicação em: novembro 2004 